\title{
Women's Health Insurance Status in Senegal West Africa
}

\author{
Rhonda BeLue ${ }^{1^{*}}$, Jeremy Green ${ }^{2}$, Adaobi Anakwe $^{3}$ and Mor Diaw ${ }^{4,5}$ \\ ${ }^{1}$ Health Policy and Management, Saint Louis University, USA \\ ${ }^{2}$ Division of Public Health and Health Sciences, California State University, Dominguez Hills, USA \\ ${ }^{3}$ Department of Epidemiology and Biostatistics, Saint Louis University, USA \\ ${ }^{4}$ Laboratoire de Physiologie et Explorations Fonctionnelles, Faculté de Médecine, Pharmacie et Odontologie Université \\ Cheikh Anta Diop de Dakar, Sénégal \\ ${ }^{5}$ Unité Mixte Internationale (UMI 3189), "Environnement, Santé, Sociétés" CNRS, UCAD, CNRST, USTTB, UGB, Dakar, \\ Sénégal
}

*Corresponding author: Rhonda BeLue, PhD, Health Management and Policy, College for Public Health and Social Justice, Saint Louis University, USA

\begin{abstract}
Background: Senegalese women of childbearing age continue to be disproportionately affected by communicable and noncommunicable disease, yet still face reduced health care access despite the expanding coverage of universal health insurance schemes. There is need to understand the role of women's socio-demographic positioning and household decision-making autonomy on their health care insurance participation.

Method: We analyzed data from a representative sample from the 2016 Senegalese Demographic and Health Surveys (DHS) using logistic regression models to examine the association between women's insurance coverage and socio-demographic correlates including women's household decision making autonomy.

Results: The final study sample included a total of 1308 Senegalese women (age extremes: 15 and 49 years). Most women were 30 to 34 years $(23.6 \%)$, did not have any formal education $(59.4 \%)$, could not read at all $(67 \%)$ and did not have health insurance (89.3\%). Socio-demographic factors were significantly associated with health insurance enrollment. The probability of being enrolled in health insurance was 16.4 percentage points higher among women with the greatest wealth, as compared to those with the least wealth (95\% confidence interval, 9.7 to 23.1). The probability of being enrolled in health insurance was 5.9 percentage points higher among women with any education, as compared to those with no education (95\% confidence interval, 0.7 to 11.1 ). Household decision-making autonomy was not associated with insurance coverage.
\end{abstract}

Conclusion: Our study not only highlights the disparities in health insurance uptake in this population but also suggests a need for studies, especially among women in resourcelimited households, that shed light on how to best design, market, and improve uptake of health insurance among women.

\section{Keywords}

Decision-making autonomy, Women, Senegal, Health insurance

\section{Background}

Women of childbearing age in sub-Saharan Africa (SSA) remain an important focal point for health-access related research and interventions. Globally, about 1.3 billion people do not have access to affordable health care and those in low- and middle-income countries (LMICS), often bear a disproportionate burden of disease, have reduced access to health care [1]. It is thought that if women have improved access to health care, their health outcomes, particularly around childbirth related mortalities, can be reduced [2]. Enrollment in insurance schemes is widely acknowledged as a tool to increase health access by financing health care provision in low-income countries, which can mitigate catastrophic health services expenditures [3-5].

Women in Senegal, like in most SSA countries, continue to be disproportionately affected by a host

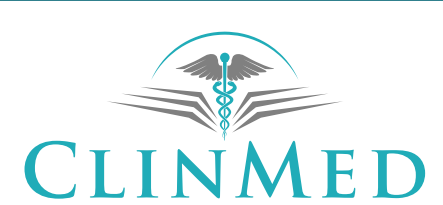

INTERNATIONAL LIBRARY 
of preventable health conditions including chronic and infectious diseases that contribute to maternal morbidity and mortality [6]. In 2017, Senegal reported a maternal mortality rate of 315 per 100,000 live births compared to the less than 50 deaths per 100,000 live births reported by most high-income countries [7]. Even though a marked increase in insurance coverage was observed from $20 \%$ in 2012 to $49.6 \%$ in 2018 across the general population, this increase lagged behind the $65 \%$ proposed Universal Health Coverage (UHC) goals of the Senegal government by 2015 [8-10]. Among Senegalese women, however, mixed findings were reported on factors that contribute to access and utilization of health services [11], and suggest a need to understand both the structural components of health insurance as provided in Senegal and the facilitators and barriers to women's enrollment in these health insurance schemes.

Health care and access through health insurance schemes in Senegal are nascent and emerging. Broadly, Senegal runs a pluralistic health insurance system that includes both public and private options with the public sector broken into three parts: The Institut de Prévoyance Maladie (IPM) health fund, communitybased health insurance (CBHI), and Plan Sesame (PS). While the IPM and $\mathrm{CBHI}$ schemes were provided to the young and active persons, PS was created to cater to the health needs of the elderly population [12]. IPM is a payroll-based mandatory social health insurance for formal sector workers and covers up to 80 percent of medical, pharmaceutical, and hospital costs for the $11 \%$ of employees in this sector $[9,10]$. Because most of the population (80\%) works in the informal sector, $\mathrm{CBHI}$ schemes began developing in Senegal in the 1980s [10]. CBHI originates at the community level, either by community members, non-governmental organizations, or health services providers. CBHI members pay a premium, and the Senegalese government also contributes to the funds financially [13]. However, it is estimated that only $4.8 \%$ of the population have coverage under $\mathrm{CBHI}$ [9]. Most payments for health care in Senegal like in most LMICs are made through out-ofpocket payments. However, in LMICs where women are underrepresented in the employment workforce or have less decision-making autonomy it remains unclear the extent to which these factors can influence women's enrollment and participation in health insurance.

Socio-demographic factors including age at first marriage, educational status, poverty level, marital status and decision-making autonomy may influence women's ability to enroll in insurance schemes. Women's autonomy, often defined within the context of a woman's ability to participate in decision making for her health care, freedom to visit family, ability to make household purchases and decision on activities was positively associated with women's access to and utilization of health care [3,14-16]. Also, older age at first marriage and higher education were associated with higher autonomy and more enrollment in insurance schemes [16]. Family size was also associated with enrollment in community-based insurance schemes. Basaza, et al. (2008) found that families with a larger size had more competing responsibilities and were at higher risk for non-enrollment in health insurance [17]. Further, women who are older, live in urban areas, attained higher education and had their own source of income had more health care seeking and utilization autonomy [18]. A study that examined insurance enrollment through mutual health organizations in Ghana, Mali and Senegal found that enrollment in an insurance scheme was more likely among families that have a female household head, an educated household head or wealthier families. However, families enrolled in the insurance scheme in Senegal were less likely than residents in Ghana and Mali to seek formal health care [3]. These findings indicate a need to examine factors that may contribute to this trend in Senegal.

Although several studies have found a positive association between women's autonomy and utilization of health care resources $[11,18]$ albeit weak, research on the role of women's autonomy on health insurance enrollment and utilization is sparse in the literature. Conflicting results were also reported in Senegal in terms of women's autonomy and utilization of birth assistants [11]. While there are several insurance options available to Senegalese residents, insurance coverage remains low. Despite the acknowledgements that access to health insurance can reduce economic barriers to health care and increase utilization, it remains unclear the extent to which women in Senegal are able to enroll in these insurance schemes given their family decision making autonomy and other socio-demographic factors. Therefore, the purpose of this study was to assess women's health insurance enrollment status and identify socio-demographic correlates of insurance coverage in a national sample of Senegalese families.

\section{Materials and Methods}

\section{Procedures}

We used extant data from the 2016 Senegalese Demographic and Health Surveys (DHS). The DHS are a project of the United States Agency for International Development and aim to provide high quality data on population demographics and health status measures. The DHS program began in 1984 and seeks to generate data that can be used by policymakers and related stakeholders. DHS data are collected through interviews by field staff. The data consist of a woman's questionnaire, a man's questionnaire, a household questionnaire and later, a biomarker questionnaire and a fieldworker's questionnaire. Survey sampling is conducted at the household level, with the woman's questionnaire being the primary focus of the data collection. Data are collected from women of reproductive age (15 through 49 years) [19]. 


\section{Measures}

Measures of interest in the Senegal DHS included insurance status, socio-demographic characteristics, and decision-making variables. Our main variable of interest was whether or not the individual woman surveyed by the DHS was or was not covered by health insurance. In addition to our main interest in insurance, our secondary interest was socio-demographic characteristics of the study sample, and how these demographic characteristics might be related to insurance status. For our demographic measures, we included age in 5-year groups (15-24, 25-29, 30-34, 35$39,40-44$, and 45-49 years), educational attainment (no education, any education), literacy level (cannot read at all, able to read only parts of sentences, able to read whole sentences, no card with required language available, and blind/visually impaired), wealth index (poorest, poorer, middle, richer, richest), and marital status (never in union, married, living with partner, widowed, divorced, no longer living together/ separated). Only married women were included in our final sample because questions on decision-making were asked in just this sub-population.

For decision making measures, we included a series of five variable groups from the Senegal DHS: (1) Who usually decides how the money you earn will be used: you, your (husband/partner), or you and your (husband/partner) jointly? (2) Who usually decides how your (husband's/partner's) earnings will be used: You, your (husband/partner), or you and your (husband/ partner) jointly? (3) Who usually makes decisions about health care for yourself: You, your (husband/partner), you and your (husband/partner) jointly, or someone else? (4) Who usually makes decisions about making major household purchases? and (5) Who usually makes decisions about visits to your family or relatives? These variables were recategorized into autonomous (if a woman made the decision by herself or jointly with her husband/partner) and not autonomous (if the woman was not involved in the decision-making process at all). Finally, we developed a summary score where women received a point for each autonomous decision-making category resulting in a score between 0 and 5 .

\section{Analytic approach}

Our analysis plan began with a description of the socio-demographic characteristics of the women in the study sample, followed by a more detailed description of insurance coverage, as related to each of the sociodemographic characteristics included in the analysis. First, we tabulated each of the socio-demographic characteristics to generate counts and frequencies of each individual in the study sample corresponding to each of the demographic characteristics of interest. Second, we cross-tabulated each of the demographic characteristics of individuals in the study sample by insurance status, to stratify the counts and frequencies of each characteristic by the dichotomous measure of having or not having health insurance. Third, we used Chi-square tests to verify the hypothesis that insurance status could vary with the demographic characteristics of individuals in the study sample. We reported the resulting $p$-values to describe the variation in insurance status by the demographic characteristics.

For the decision-making analysis, we began by tabulating each of the decision-making variables, separately, to generate counts and frequencies of each response category under each of the decisionmaking questions of interest. Lastly, we employed logistic regression to assess the relationship between the outcome, insurance status and socio-demographic and decision-making variables. Variance inflation factors were calculated to test the regression model for collinearity [20]. All analyses were conducted in STATA 15 [21] and the statistical significance was defined as $p$ $<0.05$.

\section{Results}

The final study sample included a total of 1308 Senegalese women aged 15 and 49 years. Table 1 reported the descriptive characteristics of the study sample for the individual women's dataset in the 2016 Senegalese DHS files. The first column of Table 1 described the socio-demographic characteristics of the study sample, in categories. The second through fourth columns of Table 1 reported the frequency (\%) of each category of a given descriptive statistic and count (No or Yes), where the frequencies sum to $100 \%$ within each characteristic. The fifth and final column of Table 1 represented p-values from Chi-square test of the hypothesis that insurance status varied statistically significantly between individuals in different categories of demographic characteristics. This table showed that $23.7 \%$ of the sample is 30 to 34 -years-old, $59.4 \%$ of the sample had not completed any formal education by the time that they were interviewed for the DHS project, $67 \%$ of individuals could not read at all, $21.2 \%$ were in the poorest wealth category, and $89.3 \%$ were not covered by health insurance. This table indicated that insurance status varied significantly with educational attainment, literacy level, wealth, and ethnicity, but not with age category.

Results from our decision-making analysis highlight that, in the Senegal DHS, most women reported that their husbands and partners made decisions, rather than the women themselves except for decision-making on contraceptives. Husbands and partners made $81.4 \%$ of the decisions on women's health care, $82.6 \%$ of decisions on large household purchases, $88.6 \%$ of decisions on visits to family or relatives, and $83.2 \%$ of decisions on what to do with money that the husband earns. By contrast, $88.2 \%$ of contraceptive decisions 
Table 1: Descriptive characteristics of the study sample for individual Women's data by Insurance Status $(n=1308)$.

\begin{tabular}{|c|c|c|c|c|}
\hline \multirow[b]{2}{*}{ Variable } & \multirow[b]{2}{*}{$\begin{array}{c}\text { Total } \\
\text { (\%) }\end{array}$} & \multicolumn{2}{|c|}{ Insurance status } & \multirow[b]{2}{*}{ p-value } \\
\hline & & $\begin{array}{c}\text { No }=1,168 \\
n(\%)\end{array}$ & $\begin{array}{c}\text { Yes }=140 \\
n(\%)\end{array}$ & \\
\hline \multicolumn{5}{|l|}{ Age } \\
\hline $15-24$ & $209(100.0)$ & $191(91.4)$ & $18(8.6)$ & 0.696 \\
\hline $25-29$ & $272(100.0)$ & $247(90.8)$ & $25(9.2)$ & \\
\hline $30-34$ & $310(100.0)$ & $272(87.7)$ & $38(12.3)$ & \\
\hline $35-39$ & $236(100.0)$ & $209(88.6)$ & $27(11.4)$ & \\
\hline $40-44$ & $180(100.0)$ & $161(89.4)$ & $19(10.6)$ & \\
\hline $45-49$ & $101(100.0)$ & $88(87.1)$ & $13(12.9)$ & \\
\hline \multicolumn{5}{|l|}{ Education status } \\
\hline No education & $777(59.4)$ & 739 (95.1) & $38(4.9)$ & $<0.0001$ \\
\hline Any education & $531(100.0)$ & $429(80.8)$ & $102(19.2)$ & \\
\hline \multicolumn{5}{|l|}{ Literacy } \\
\hline Cannot read at all & $876(67.0)$ & $826(94.3)$ & $50(5.7)$ & $<.0001$ \\
\hline Able to read only partial & $107(8.2)$ & $90(84.1)$ & $17(15.9)$ & \\
\hline Able to read whole sentence & $325(24.9)$ & $252(77.5)$ & $73(22.5)$ & \\
\hline \multicolumn{5}{|l|}{ Wealth index } \\
\hline Poorest & $277(21.2)$ & $267(96.4)$ & $10(3.6)$ & $<0.0001$ \\
\hline poorer & $289(22.1)$ & $275(95.2)$ & $14(4.8)$ & \\
\hline Middle & $319(24.4)$ & $287(90.0)$ & $32(10.0)$ & \\
\hline Richer & $244(18.7)$ & $211(86.5)$ & $33(13.5)$ & \\
\hline Richest & $179(13.7)$ & $128(71.5)$ & $51(28.5)$ & \\
\hline \multicolumn{5}{|l|}{ Marital status } \\
\hline Married & $1308(100.0)$ & 1168 (89.3) & $140(10.7)$ & - \\
\hline \multicolumn{5}{|l|}{ Ethnicity } \\
\hline Wolof & $511(39.1)$ & $456(89.2)$ & $55(10.3)$ & 0.001 \\
\hline Poular & $355(27.1)$ & 319 (89.9) & $36(10.1)$ & \\
\hline Serer & $203(15.5)$ & $186(91.6)$ & $17(8.4)$ & \\
\hline Mandingue & $108(8.3)$ & $101(93.5)$ & $7(6.5)$ & \\
\hline Diola & $49(3.8)$ & $35(71.4)$ & $14(28.6)$ & \\
\hline Soninke & $8(0.61)$ & $7(87.5)$ & $1(12.5)$ & \\
\hline Not Senegalese & $24(1.8)$ & $23(95.8)$ & $1(4.2)$ & \\
\hline Other & $50(3.8)$ & $41(82.0)$ & $9(18.0)$ & \\
\hline Big City & & & & 0.036 \\
\hline Not a big city & 707 (100.0) & $643(91.0)$ & $64(9.1)$ & \\
\hline Big city & $601(100.0)$ & $525(87.4)$ & $76(12.7)$ & \\
\hline
\end{tabular}

were made jointly by women and their husbands or partners (Table 2).

Table 3 represented results from logistic regression models. Results showed that having insurance is mostly dependent on socio-economic status. The probability of being enrolled in health insurance was 16.4 percentage points higher among women with the greatest wealth, as compared to those with the least wealth $(95 \%$ confidence interval, 9.7 to 23.1 ). The probability of being enrolled in health insurance was 5.9 percentage points higher among women with any education, as compared to those with no education ( $95 \%$ confidence interval, 0.7 to 11.1). Household decision-making autonomy was not associated with insurance coverage. In Appendix Table 1 we report the variance inflation factors which, being below the recommended threshold of 10 [20], show no meaningful evidence of collinearity.

\section{Discussion}

This study examined the socio-demographic correlates of health insurance enrollment among Senegalese women. Overall, only about $10 \%$ of women were insured and these women were more educated, more literate, wealthier, and belonged mostly to the 
Table 2: Descriptive statistics of family decision making autonomy by insurance status $(n=1308)$.

\begin{tabular}{|c|c|c|c|c|}
\hline \multirow[b]{2}{*}{ Variable } & \multirow[b]{2}{*}{ Total } & \multicolumn{2}{|c|}{ Insurance status } & \multirow[b]{2}{*}{ p-value } \\
\hline & & $\begin{array}{c}\text { No } \\
\text { n (\%) }\end{array}$ & $\begin{array}{c}\text { Yes } \\
\text { n (\%) }\end{array}$ & \\
\hline \multicolumn{5}{|l|}{ Own health care } \\
\hline Autonomous & $243(18.6)$ & $221(91.0)$ & $22(9.1)$ & 0.357 \\
\hline Not autonomous & $1065(81.4)$ & 947 (88.9) & $118(11.1)$ & \\
\hline \multicolumn{5}{|c|}{ Major household purchases } \\
\hline Autonomous & $228(17.4)$ & $209(91.7)$ & $19(8.3)$ & 0.203 \\
\hline Not autonomous & $1080(82.6)$ & $959(88.8)$ & $121(11.2)$ & \\
\hline \multicolumn{5}{|l|}{ Visits to family or relatives } \\
\hline Autonomous & $149(11.4)$ & $135(90.6)$ & $14(9.4)$ & 0.583 \\
\hline Not autonomous & $1159(88.6)$ & $1033(89.1)$ & $126(10.9)$ & \\
\hline \multicolumn{5}{|c|}{ Decides on husbands' earnings } \\
\hline Autonomous & $220(16.8)$ & $195(88.6)$ & $25(11.4)$ & 0.728 \\
\hline Not autonomous & $1088(83.2)$ & $973(89.4)$ & $115(10.6)$ & \\
\hline \multicolumn{5}{|l|}{ Contraceptive use } \\
\hline Autonomous & $1153(88.2)$ & 1025 (88.9) & $128(11.1)$ & 0.204 \\
\hline Not autonomous & $155(11.9)$ & $143(92.3)$ & $12(7.7)$ & \\
\hline Decision making score ${ }^{*}$ & & & & 0.802 \\
\hline 0 & $108(8.3)$ & $99(91.7)$ & $9(8.3)$ & \\
\hline 1 & $804(61.5)$ & $714(88.8)$ & $90(11.2)$ & \\
\hline 2 & $189(14.5)$ & $166(87.8)$ & $23(12.2)$ & \\
\hline 3 & $76(5.8)$ & $70(92.1)$ & $6(7.9)$ & \\
\hline 4 & $72(5.5)$ & $66(91.7)$ & $6(8.3)$ & \\
\hline 5 & $59(4.5)$ & $53(89.8)$ & $140(10.7)$ & \\
\hline
\end{tabular}

*: sum score of women's decision-making autonomy from 0: No autonomy to 5: Autonomous in all five domains.

Table 3: Logistic regression model on decision making characteristics of the study sample for individual women's data $(n=1308)$.

\begin{tabular}{|c|c|c|c|c|c|}
\hline \multirow{2}{*}{ Variable } & & \multirow{2}{*}{$\begin{array}{c}\text { Incremental } \\
\text { Effect }\end{array}$} & \multicolumn{2}{|c|}{$95 \%$ confidence interval } & \multirow[t]{2}{*}{ p-value } \\
\hline & & & Lower bound & Upper bound & \\
\hline \multirow[t]{6}{*}{ Age } & $15-24-$ ref & & & & \\
\hline & $25-29$ & 0.0137305 & -0.0428794 & 0.0703404 & 0.635 \\
\hline & $30-34$ & 0.0499299 & -0.0034563 & 0.1033161 & 0.067 \\
\hline & $35-39$ & 0.0488583 & -0.0084567 & 0.1061733 & 0.095 \\
\hline & $40-44$ & 0.050331 & -0.0118615 & 0.1125235 & 0.113 \\
\hline & $45-49$ & 0.0795627 & 0.0082868 & 0.1508386 & 0.029 \\
\hline \multirow[t]{2}{*}{$\begin{array}{l}\text { Education } \\
\text { status }\end{array}$} & No education -ref & & & & \\
\hline & Any education & 0.0589362 & 0.0074993 & 0.1103731 & 0.025 \\
\hline \multirow[t]{3}{*}{ Literacy } & Cannot read at all-ref & & & & \\
\hline & Able to read only partial & 0.0374329 & -0.0231827 & 0.0980485 & 0.226 \\
\hline & Able to read whole sentence & 0.0575859 & 0.0076561 & 0.1075158 & 0.024 \\
\hline \multirow[t]{5}{*}{ Wealth index } & Poorest - ref & & & & \\
\hline & poorer & 0.0214799 & -0.0502267 & 0.0931866 & 0.557 \\
\hline & Middle & 0.068564 & 0.0028001 & 0.1343279 & 0.041 \\
\hline & Richer & 0.093165 & .0266414 & 0.1596886 & 0.006 \\
\hline & Richest & 0.1636425 & 0.0967245 & 0.2305605 & 0.000 \\
\hline
\end{tabular}




\begin{tabular}{|l|l|c|c|c|c|}
\hline $\begin{array}{l}\text { Decision } \\
\text { making score }\end{array}$ & 0 - ref & & & & \\
\hline & 1 & 0.0121508 & -0.052156 & 0.0764577 & 0.711 \\
\hline & 2 & -0.0047259 & -0.0778918 & 0.06844 & 0.899 \\
\hline & 3 & -0.0477056 & -0.1459398 & 0.0505285 & 0.341 \\
\hline & 4 & -0.0244915 & -0.1231535 & 0.0741704 & 0.627 \\
\hline & 5 & -0.0066096 & -0.1043342 & 0.0911151 & 0.895 \\
\hline Big city & Other & 0.0441662 & -0.0272239 & 0.1155563 & 0.225 \\
\hline & Not a big city - ref & & & & .054672 \\
\hline
\end{tabular}

Note: Ethnicity also NS; NS: Not statistically significant.

Diola ethnic group. Although most women did not have decision making autonomy, except on decisions around contraceptives, women's decision-making autonomy was not associated with insurance enrollment status. Other socio-demographic factors like rural/urban residence, literacy and age were also not associated with enrollment in insurance. These findings highlight the role of women's socioeconomic status on health insurance enrollment.

Consistent with the literature on utilization of health care services and higher socioeconomic status, our study found that Senegalese women who were wealthier and of higher education status were more likely to enroll in health insurance. This positive effect of wealth on women's health insurance enrollment and utilization of health care services is well documented in the literature $[22,23]$. Our study further showed a dose-response pattern around wealth with consistent increases in the odds of enrollment as wealth increased. However, only a small proportion of Senegalese women fell into the richer/richest wealth categories. Similarly, in Senegal women's higher education status showed increased odds for insurance enrollment, but less than $3 \%$ of women had more than a secondary education. These phenomena suggest that bridging wealth and education gaps could improve the health status of Senegalese women by increasing their enrollment in health insurance schemes [24]. Strategies to close these gaps should remain a national priority if the health of women in Senegal will be improved.

Our study found that most women did not have decision making autonomy, except on decisions around contraceptive use. An inverse association was observed between women's decision-making autonomy and health insurance enrollment, albeit non-significant. This finding was consistent with other studies that found an inverse relationship between women's decisionmaking autonomy on household purchases and lower odds for utilizing maternal healthcare specific services in a Senegalese population [11]. This finding however contrasts with previous studies in other SSA and LMICs where a positive association was found between women's autonomy and utilization of maternal health specific services $[11,15]$. This disparity raises questions about the mechanism by which women's enrollment in insurance schemes occurs in Senegal. Explanations could be nested in economic and/or cultural factors or the structures of these insurance schemes themselves [15]. It has been suggested that factors inherent in the insurance structure such as payment modalities, level of premium and benefits package may influence enrollment $[2,25,26]$. More in-depth studies are needed to examine the mechanism by which decision-making autonomy among Senegalese women influences insurance coverage and utilization.

While our sample was a representative of women in Senegal, our study is not without limitations. First, measures of woman's overall health status and details of family household structure were unavailable. Measures related to health services utilization and need for medical care were also not available. There is a need for more studies that utilize both qualitative and longitudinal data to elucidate the autonomy-insurance utilization pathway(s). Next steps in understanding health insurance uptake and the benefits of health care insurance should include qualitative interviews with women and their families to identify the understanding of how to obtain, barriers to obtaining and perceived utility of having health insurance. This is especially critical for women in limited resource households that are eligible for $\mathrm{CBHI}$. More in-depth study may shed light on how to best design, market, and improve uptake of health insurance among women with limited access to education and resources.

\section{Declaration of Interest Statement}

None.

\section{References}

1. Asfaw A, Jütting JP (2007) The role of health insurance in poverty reduction: Empirical evidence from Senegal. International Journal of Public Administration 30: 835-858.

2. Smith KV, Sulzbach S (2008) Community-based health insurance and access to maternal health services: Evidence from three West African countries. Soc Sci Med 66: 24602473.

3. Chankova S, Sulzbach S, Diop F (2008) Impact of mutual 
health organizations: Evidence from West Africa. Health policy and planning 23: 264-276.

4. Ekman B (2004) Community-based health insurance in low-income countries: A systematic review of the evidence. Health Policy and Planning 19: 249-270.

5. Jakab M, Preker AS, Krishnan C, Schneider P, Diop F, et al. (2001) Social inclusion and financial protection through community financing: Initial results from five household surveys. Open Knowledge Repository.

6. World Health Organization (2016) Senegal - Country cooperation strategy at a glance.

7. UNICEF (2019) Maternal Mortality.

8. Agence de la Couverture Maladie Universelle (2019) Major performances of CMU.

9. Daff BM, Diouf S, Diop ESM, Mano Y, Nakamura R, et al. (2020) Reforms for financial protection schemes towards universal health coverage, Senegal. Bulletin of the World Health Organization 98: 100-108.

10. Tine J, Hatt L, Faye S, Nakhimovsky S (2014) Universal health coverage measurement in a lower-middle-income context: A Senegalese case study. Health Finance \& Governance Project, Abt. Associates Inc, Bethesda, MD.

11. Chol C, Negin J, Agho KE, Cumming RG (2019) Women's autonomy and utilisation of maternal healthcare services in 31 Sub-Saharan African countries: results from the demographic and health surveys, 2010-2016. BMJ Open 9: e023128.

12. Mladovsky $P, B a M(2017)$ Removing user fees for health services: A multi-epistemological perspective on access inequities in Senegal. Social Science \& Medicine 188: 9199.

13. Zelelew HN (2015) Community health financing as a pathway to universal health coverage: Synthesis of evidence from Ghana, Senegal, and Ethiopia.

14. Corroon M, Speizer IS, Fotso J-C, Akiode A, Saad A, et al. (2014) The role of gender empowerment on reproductive health outcomes in urban Nigeria. Maternal and Child Health Journal 18: 307-315.

15. Osamor PE, Grady C (2016) Women's autonomy in health care decision-making in developing countries: A synthesis of the literature. International Journal of Women's Health 8: 191-202.
16. Shimamoto K, Gipson JD (2015) The relationship of women's status and empowerment with skilled birth attendant use in Senegal and Tanzania. BMC Pregnancy Childbirth 15: 154.

17. Basaza R, Criel B, Van der Stuyft P (2008) Community health insurance in Uganda: Why does enrolment remain low? A view from beneath. Health Policy 87: 172-184.

18. Nigatu D, Gebremariam A, Abera M, Setegn T, Deribe K (2014) Factors associated with women's autonomy regarding maternal and child health care utilization in Bale Zone: A community based cross-sectional study. BMC Women's Health 14: 79.

19. Agence Nationale de la Statistique et de la Démographie - ANSD/Sénégal, \& ICF (2017) Senegal Enquête Démographique et de Santé Continue (EDS-Continue) 2016.

20. Marquardt DW (1970) Generalized inverses, ridge regression, biased linear estimation, and nonlinear estimation. Technometrics 12: 591-612.

21. StataCorp L (2017) Stata: Statistics/data analysis (Version 15: 1 IC edition). StataCorp LLC, College Station, TX.

22. Oraro T, Ngube N, Atohmbom GY, Srivastava S, Wyss K (2018) The influence of gender and household headship on voluntary health insurance: The case of North-West Cameroon. Health Policy Plan 33: 163-170.

23. Shimamoto K, Gipson JD (2017) Examining the mechanisms by which women's status and empowerment affect skilled birth attendant use in Senegal: A structural equation modeling approach. BMC Pregnancy Childbirth 17: 341 .

24. Ahmed S, Creanga AA, Gillespie DG, Tsui AO (2010) Economic status, education and empowerment: implications for maternal health service utilization in developing countries. PLoS One 5: e11190.

25. De Allegri M, Sanon M, Bridges J, Sauerborn R (2006) Understanding consumers' preferences and decision to enrol in community-based health insurance in rural West Africa. Health Policy 76: 58-71.

26. Sagna O, Seck I, Dia A, Sall F, Diouf S, et al. (2016) Study of the Consumers' preference on the universal health coverage development strategy through health mutual in Ziguinchor Region, Southwest of Senegal. Bulletin de la Societe de Pathologie Exotique 109: 195-206. 
AppendixTable 1: Variance Inflation Factors.

\begin{tabular}{|l|l|}
\hline Variable & Variance Inflation Factor \\
\hline Age Category & \\
\hline $25-29$ & 2.08 \\
\hline $30-34$ & 2.25 \\
\hline $35-39$ & 2.02 \\
\hline $40-44$ & 1.83 \\
\hline $45-49$ & 1.51 \\
\hline Any education & 4.15 \\
\hline Literacy & \\
\hline Able to read only partial & 1.47 \\
\hline Able to read whole sentence & 3.1 \\
\hline Wealth & \\
\hline Poorer & 1.98 \\
\hline Middle & 2.17 \\
\hline Richer & 2.03 \\
\hline Richest & 1.93 \\
\hline Big city & 2.29 \\
\hline Ethnicity & 1.39 \\
\hline Poular & 1.73 \\
\hline Serer & 1.44 \\
\hline Mandingue & 1.27 \\
\hline Diola & 1.19 \\
\hline Soninke & 1.03 \\
\hline Not a Senegalese & 1.07 \\
\hline Other & 1.16 \\
\hline Decision making score & 5.41 \\
\hline 1 & 2.18 \\
\hline 2 & 1.52 \\
\hline 3 & 1.45 \\
\hline 4 & \\
\hline 5 & \\
\hline
\end{tabular}

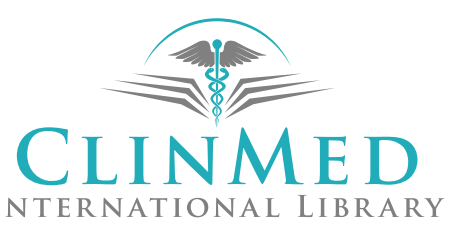

